\title{
Um jardim zoológico que não é de cristal
} Maria Helena Serôdio

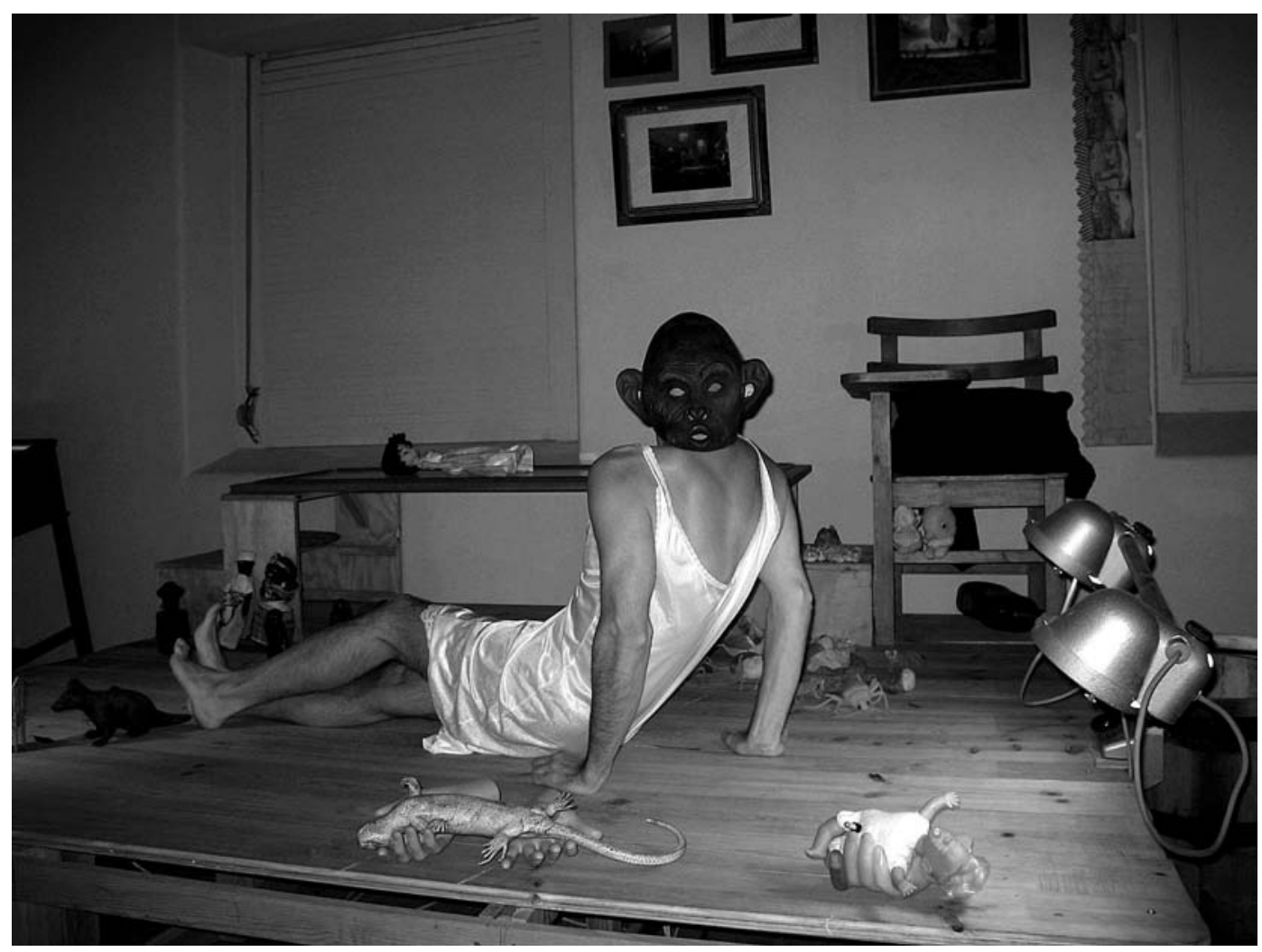

Escravo doutros, dir. Luis Castro, coreografia de Gil Mendo, Karnart, 2005 (Luis Castro), fot. Vel Z.

Titulo: Escravo doutros. Direcção e interpretação: Luis Castro. Propostas artisticas: Gil Mendo, Mark Deputter, Silvia Real, Vera Mantero, Amélia Bentes e Miguel Pereira. Coordenação artística e imagem para divulgação: Vel Z. Direcção técnica e contra-regra: Ricardo Cruz. Montagem: Marco Patrocinio, David Mesquita e Ricardo Cruz. Apoio à criação de luz: João Lopes Alves. Co-criação e operação de som: Sérgio Henriques. Operação de luz: David Mesquita. Grafismo: João Leonardo e Vel Z. Fotografias de cena: Vel Z e Maria Campos. Apoio aos figurinos: Fernanda Ramos. Produção executiva: Gisela Barros, João Pedro Branco e Susana; Produção: Karnart C.P.O.A.A. Local e data de estreia: Espaço Karnart, Lisboa, 20 de Janeiro de 2005.

Reivindicando a singularidade de um conceito para o seu trabalho - "perfinst" -, Luis Castro vem construindo um território de expressão artística onde convergem não apenas a matriz da performance e da instalação (que perfazem o conceito que elegeu como seu), mas também um trabalho muito elaborado sobre o próprio corpo, as recordações, os afectos, pequenos objectos a manipular em cena', tudo, enfim, numa panóplia de soluções visuais que lhe asseguram um universo performativo muito próprio.

Na sua carreira atravessou realidades diversas desde o Teatro da Universidade Técnica (onde se iniciou em 1982), passando por cursos de formação em Londres (entre 1995 e 1997), interpretações no Teatro Aberto (com A rua, de Jim Cartwright, 1988), a Casa da Comédia, a Pró Tea, a Cornucópia, a Escola de Mulheres (magnífico nas figuras de Joshua e Gerry, de Sétimo céu, de Caryl Churchill, 1997) e o CCB, entre outros, mas foi cada vez mais encaminhando a sua vontade de expressão para produções próprias em que o elemento de reconstrução do seu imaginário parecia exigir um confessionalismo, a que, de resto, se entregou com um indisfarçado deleite. Foi talvez a trilogia Moç+amor (1999) que consagrou publicamente a sua autobiografia espiritual, por nela se cruzarem recordações de infância, a aprendizagem do corpo e das relações consigo e com os outros, imagens fugidias de uma cena política ligada à descolonização, uma visão crítica (tocada por alguma autoironia), um gosto muito seu de percorrer um acervo de fotografias, pequenos objectos pessoais, recorte de figurinos, quase sempre em lugares não especificamente teatrais. A Galeria Zé dos Bois, a Sala de Risco, ou outros lugares menos marcados pela "tradição teatral" revelavam-se mais adequados à exposição do seu mundo, a que se colava um rosto muito singular: anguloso mas perfeitamente simétrico,
Não é por acaso que as iniciais que enigmaticamente se alinham à frente de Karnart significam Criação e Produção de Objectos Artísticos, Associação. 
orelhas destacadas, olhos largos e expressivos, rasgado no sorriso, voz bem silabada, uma expressão entre o espanto e a alegria de um encontro. Mas, curiosamente, Luis Castro revela-se também disponível para engendrar rapidamente respostas "políticas" - de assumida contestação -

relativamente a questões candentes (como a da interrupção voluntária da gravidez, contra a guerra ou a propósito de matérias do foro religioso), ao mesmo tempo que não rejeita originais revisitações a textos clássicos, como por duas vezes fez ao universo de Bernardo Santareno (0 pecado de João Agonia, 1998, ou António marinheiro, 2002) e uma ao de Federico Garcia Lorca (Yerma, 2005).

Fixado agora num lugar cedido pela Faculdade de Veterinária (que frequentou em tempos), é nesse espaço Karnart que o vemos reconfigurar o seu universo performativo, que se assume conscientemente como uma procura identitária, em que a questão do sexo e do género se articulam com uma visão política - rebelde, mas mais interrogativa que assertiva -, delas derivando pontos axiais de uma cartografia expressiva muito pessoal.

Para este espectáculo convidou seis coreógrafos a dirigi-lo, refez a grande sala colorindo-a de azul claro (uma das notas do "género" tal como tradicionalmente se impõe como próprio de meninos) e nela distribuiu espaços para as suas encenações do corpo, bem como para o público, que poderia segui-lo pelos vários lugares em que o actor se colocava. A sala longa engendrava quase a meio, encostado a uma janela à direita, um pequeno tablado, lugar primeiro de uma introdução enigmática na figura de uma velha silenciosa que se entrega à paulatina "exposição" de miniaturas. Ao fundo da sala uma porta central separava dois espaços de cena: à esquerda, fixados na parede dois quadros negros de sala de aula, com luzes de néon por cima, e, à direita, um lote de caixotes de mercadoria, um écrã na parede ao alto e um aparelho de televisão, tudo servindo a panóplia do consumo, um dos elementos fortes do espectáculo.
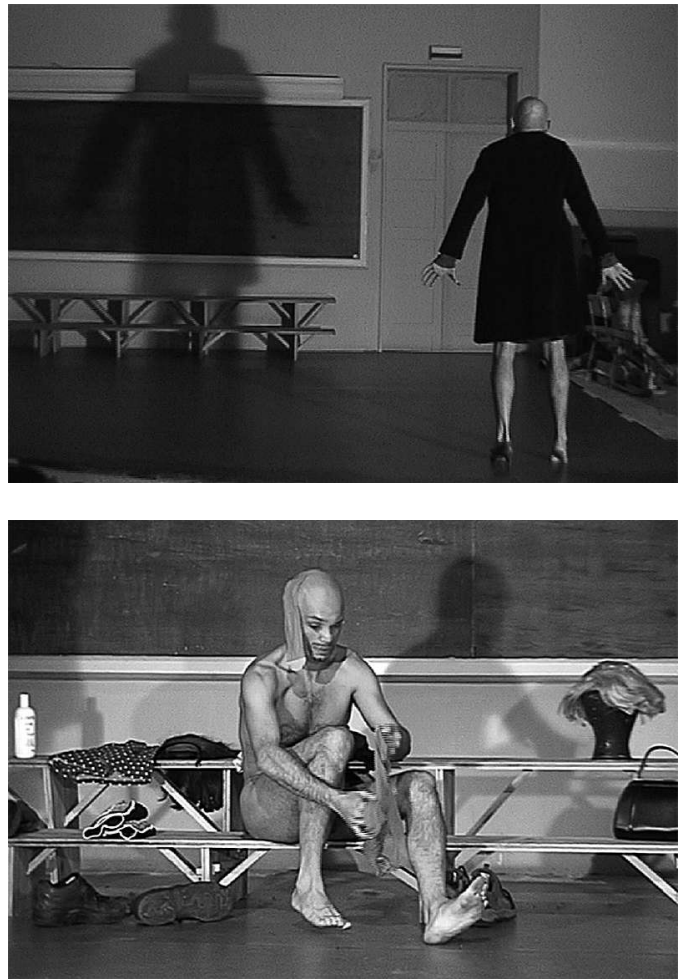

Das seis sequências criadas em conjunto com os coreógrafos, apenas uma implicava um texto a dizer Caminhantes, de Peter Handke, traduzido por João Barrento -, e que se apresentava como uma narrativa breve de uma travessia de rua, reportada a uma mulher e a uma criança, e que Luís Castro, sob a direcção de Deputter, debitava num crescendo de pavor, enquanto se deslocava ao longo da sala em linha recta na direcção da voragem da porta ao fundo. No cimo da cabeça uma máscara de tigre em cartão era sinal derrisório de um apontamento sobre a selva das cidades.

As outras sequências insistiam sobretudo na exposição do corpo: desde a mais estática espera (por uma ideia de Vera Mantero) qual Rodin pensativo, sentado perto do quadro negro, enquanto se ouvia uma canção de Ney Matogrosso, até à mais espasmódica exteriorização da rejeição do corpo - daquele corpo - sexuado, na sequência concebida com Amélia Bentes.

De Gil Mendo ficou a figuração da mulher (no tal estrado à direita), que abre de forma inesperada o espectáculo rasgando a meia cinzenta que the cobre a cara em dois pontos: o olho esquerdo e a boca. Tem na mão um feixe de objectos cinza-rosa que rapidamente identificamos como sendo de "ratos". Paulatinamente a mulher - Granny - vai retirando da mala de mão, depois de um balde e de um cesto de madeira, vários objectos de diferentes tamanhos, recuperando miniaturas de infância (mesa, cadeiras, pequenas bonecas, uma delas estranhamente com um sexo masculino vermelho) ao lado de inúmeras peças de animais, desde figurinhas de jardim zoológico a formas mais repulsivas de centopeias, ratazanas ou baratas. É um quadro lento, de paciente exposição, que constrói um universo de ansiedades e de pesadelo, ao lado do que poderia ser a benevolente recordação de jogos infantis.

Era a um ritmo totalmente diferente, quase frenético, que se desenrolava ao fundo à direita, sob proposta de 


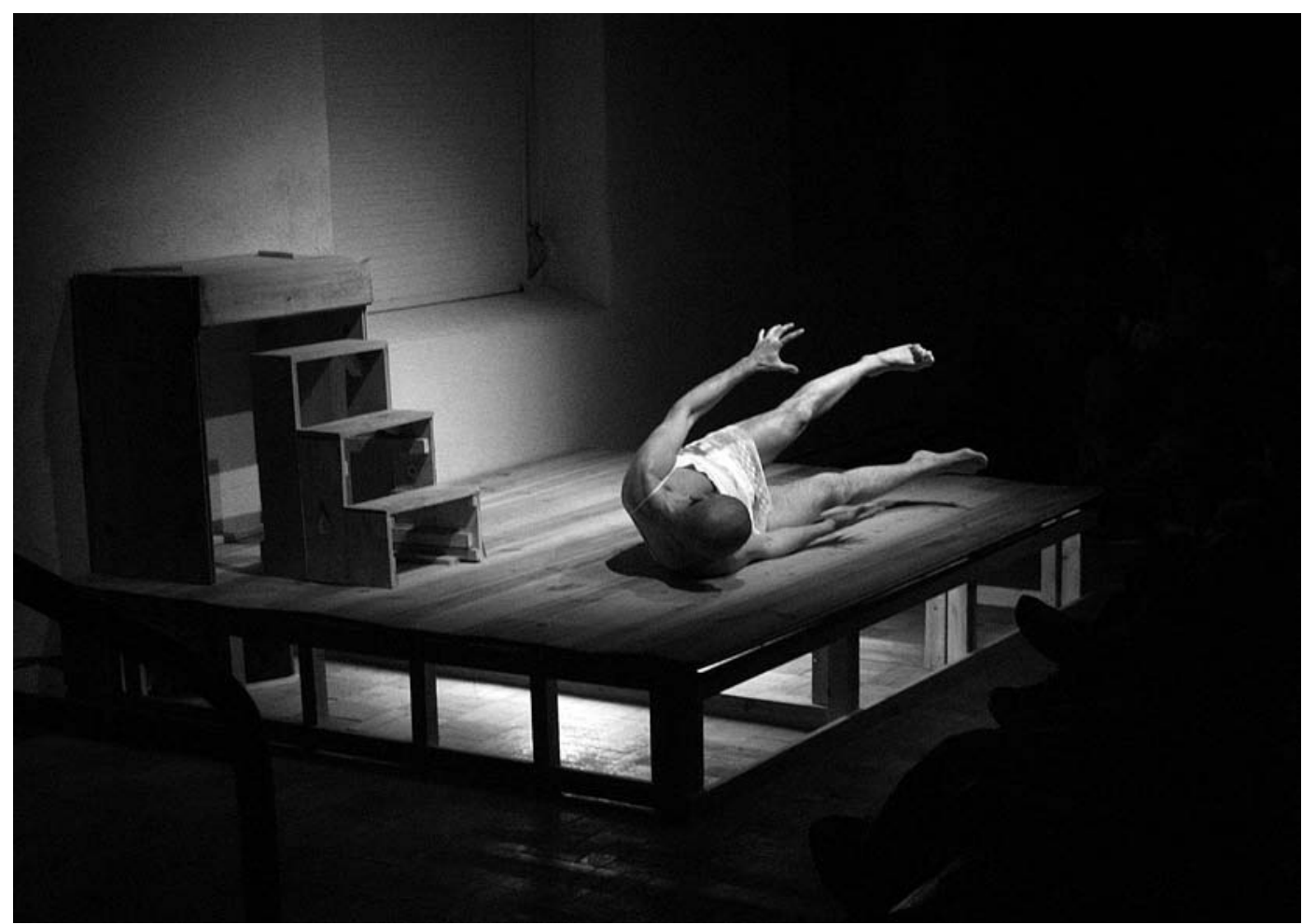

Sílvia Real, uma sucessão de gestos de desempacotar objectos, enquanto uma cafeteira eléctrica ia chiando e na televisão se ouviam anúncios e ruídos vários. 0 elemento mais importante desta sequência foi, todavia, uma cena de um filme de Roman Polanski (O inquilino, 1968) que representava um prédio de gente estranha, desvendada à janela, como se se tratasse de camarotes de teatro ou pequenos palcos por detrás de bambolinas e cortinas de cena, onde essas pessoas, os vizinhos, seriam a um tempo espectadores e insólitas personagens. De repente, precipitase do cimo do prédio uma figura humana, que se verá mais tarde ser um travesti, que cai desamparado e ferido sobre uma clarabóia, o que provoca uma reacção escandalizada por parte dos vizinhos, afinal bem mais bizarros do que a figura que hostilizam como "estranha".

A cena mais forte do espectáculo será a que Luís Castro ideou com Amélia Bentes e que decorrerá num espaço lateral oposto ao da primeira cena. Tratar-se-á de uma expressão convulsa do corpo numa quase luta agónica contra a sua forma visivel, a sua marca sexuada, que aparentemente rejeita. Em momentos vários parece recuperar, em enfurecidas metamorfoses, imagens dos animais repulsivos do $1^{\circ}$ quadro, como uma aranha que arranha o próprio corpo, ao mesmo tempo que nessa possivel mimese parece adquirir nova força a imagem de uma linda boneca de vestido branco que surgia no quadro inicial: aquela que se descobre ser o outro lado da máscara negra de borracha - a versão "obscura" do próprio actor - que ele, deitado de costas, colocará sobre o crânio para figurar o que os outros "vêem" e que em nada corresponde à idealizada auto-imagem desejada. Essa sequência de conflito físico termina com uma cena estranha e perturbadora: o actor nu no cimo de um pequeno escadote será ecrã de uma imagem que dá o outro lado do seu corpo - como se conceptualiza o "actor de sintese" de que fala Béatrice Picon-Vallon (1998: 10) -, desta forma fazendo convergir as costas e a frente, numa sobreposição estranha, magoada, sofredora. Como se se negociassem os limites de um corpo, feito ecrã das imagens do seu "outro", criando uma ambivalência sexual, nunca assumida por inteiro, antes sinalizando o conflito irresolúvel de uma transsexualização socialmente constrangedora.

Termina o espectáculo recuperando o figurino de Granny, num esforço de rebobinar tudo para trás, o que se traduz na apresentação do título do espectáculo e outros elementos da ficha técnica e artística ditos de trás para diante (ideia de Miguel Pereira).

Fica-nos do espectáculo a memória de um corpo exibido sem arrogância, com um compromisso afectivo grande e uma vontade de esconjurar ansiedades e medos. Tudo o que poderia perfazer o conjunto de imagens (ideias e preconceitos) que se procuram impor à vida das pessoas, "escravizando-as", assim, aos outros. Mas ficam-nos também na memória momentos musicais vivos (reminiscentes da técnica do cinema) a estabelecerem a ligação entre as várias sequências, bem como o fetiche de collants cinza claro (na cara e nas pernas) e a exposição do corpo como factor primeiro da construção de uma identidade: ainda que exacerbada no repúdio, surgia ainda convivendo nos caminhos do mundo por entre as presenças furtivas do pesadelo, do sonho, dos imaginários, tanto do próprio, como dos outros. Com uma real e assumida autenticidade performativa que não podia deixar de nos perturbar e comover.

\section{Referência bibliográfica}

PICON-VALLIN, Béatrice (dir.) (1998), Les écrans sur la scène: Tentations et résistances de la scène face aux images, Lausanne, L'Age d'Homme. 